\title{
Streamflow response to regional climate model output in the mountainous watershed: a case study from the Swiss Alps
}

\author{
Kazi Rahman - Christophe Etienne $\cdot$ \\ Ana Gago-Silva $\cdot$ Chetan Maringanti • \\ Martin Beniston · Anthony Lehmann
}

Received: 8 September 2013/ Accepted: 5 May 2014/Published online: 21 June 2014

(C) Springer-Verlag Berlin Heidelberg 2014

\begin{abstract}
Regional climate model (RCM) outputs are often used in hydrological modeling, in particular for streamflow forecasting. The heterogeneity of the meteorological variables such as precipitation, temperature, wind speed and solar radiation often limits the ability of the hydrological model performance. This paper assessed the sensitivity of RCM outputs from the PRUDENCE project and their performance in reproducing the streamflow. The soil and water assessment tool was used to simulate the streamflow of the Rhone River watershed located in the southwestern part of Switzerland, with the climate variables obtained from four RCMs. We analyzed the difference in magnitude of precipitation, maximum and minimum air temperature, and wind speed with respect to
\end{abstract}

Electronic supplementary material The online version of this article (doi:10.1007/s12665-014-3336-0) contains supplementary material, which is available to authorized users.

K. Rahman $(\varangle) \cdot$ C. Etienne · A. Gago-Silva · M. Beniston · A. Lehmann

Institute for Environmental Sciences, University of Geneva,

Battelle, Building D, 7 route de Drize, 1227 Carouge,

Switzerland

e-mail: kazi.rahman@unige.ch

K. Rahman · A. Lehmann

Forel Institute, University of Geneva, 10 route de Suisse,

CP 416, 1290 Versoix, Switzerland

C. Maringanti

Risk Modeling Unit, Zurich Financial Services Ltd.,

P.O. Box 8022, Zurich, Switzerland

\section{A. Lehmann}

United Nations Environment Programme, Division of Early

Warning and Assessment, Global Resource Information

Database Geneva, International Environment House,

11 chemin des Anémones, 1219 Châtelaine, Switzerland the observed values from the meteorological stations. In addition, we also focused on the impact of the grid resolution on model performance, by analyzing grids with resolutions of $50 \times 50$ and $25 \times 25 \mathrm{~km}^{2}$. The variability of the meteorological inputs from various RCMs is quite severe in the studied watershed. Among the four different RCMs, the Danish Meteorological Institute provided the best performance when simulating runoff. We found that temperature lapse rate is significantly important in the mountainous snow and glacier dominated watershed as compared to other variables like precipitation, and wind speed for hydrological performance. Therefore, emphasis should be given to minimum and maximum temperature in the bias correction studies for downscaling climatic data for impact modeling in the mountainous snow and glacier dominated complex watersheds.

Keywords RCM - SWAT · Grid size - Runoff · Hydrological model

\section{Introduction}

Regional climate models (RCMs) are frequently used for climate change studies (Beniston and Goyette 2007; Beniston et al. 2011; Christensen et al. 2002). Since they provide climatic variables such as precipitation and temperature, they are used by hydrological modelers to simulate streamflow and flood frequency analysis for climate change studies (Ahl et al. 2008; Pradhanang et al. 2011; Wang and Melesse 2005; Zhang et al. 2008; Graham et al. 2007). The heterogeneity of the meteorological variables is often reported as a drawback for simulating a range of processes in climate models (Christensen et al. 2002). Several studies were performed on the impact of grid size 
of the digital elevation model, land use and type of soil datasets. The influences of the catchment subdivision on flow simulations were also studied, but it was seen that meteorological parameters exert the most significant influence on model performance. Different methodological inputs have been tested with hydrological models like soil and water assessment tool (SWAT) such as areal precipitation (Masih et al. 2011), interpolation techniques of radar-driven precipitation (Liechti et al. 2012), and multimodel comparison with different sources of meteorological datasets (Chen et al. 2012). Climatic data for developing hydrological models is basically of two types: one is local meteorological station data and the other is gridded data obtained from the global circulation models (GCMs) and RCMs. They are often useful when the available local meteorological data is sparse and when predicting future changes (Liu et al. 2013). Climate models provide meteorological data mostly with the reanalysis based on the availability of the local stations, and thus it is important to test the sensitivity of the individual models before applying their outputs in the watershed with varying topography.

It is obvious that the climate model generated variables are not often homogeneous to the observed variables, therefore, the bias correction studies are conducted for the impact modeling studies (Bordoy and Burlando 2012; Murphy 1999; Schoetter et al. 2012). Various techniques are used for bias correction studies starting from simple scaling to rather sophisticated method (Pavlik et al. 2012). Among the different techniques, widely accepted 'delta change approach' (Bosshard et al. 2011; Lettenmaier et al. 1999) where it is recommended to use the RCM simulated future change (e.g., anomalies) for a perturbation of observed data rather than to use direct RCM generated variables. The linear-scaling approach (Lenderink et al. 2007) works based on monthly correction values on the differences between measured and present-day model generated values. By definition, corrected RCM generated variables will perfectly agree in their monthly mean values with the observations. Meanwhile linear scaling considers for a bias in the mean, it does not account differences in the variance to be corrected. It is important to mention that high altitude watersheds where snow and glacier melt plays significant role in streamflow generation the mean value often limits the statistical performance of the model as the hydrology is quite sensitive to melt rate. Therefore, a nonlinear correction studies are often conducted (Leander and Buishand 2007), which helps to specify the adjustment of variance statistics of a precipitation time series. The advantages and limitation of various bias correction technique is beyond the scope of our study because the hydrological model structure often determines the simulated flow patterns considering the meteorological variables like mean value or minimum and maximum values as input.
In this research we focused on the built-in interpolation function of SWAT with the different sources of climate data taken from the PRUDENCE (Prediction of Regional scenarios and Uncertainties for Defining European Climate change risks and Effects) project. PRUDENCE (Christensen et al. 2002), whose aim was to test the capacity of a suite of RCMs to reproduce current European climate and to compare model projections for a "greenhouse climate" by 2100 . Outputs from this project have been used for various impact studies, such as discharge estimations (Beniston 2010) and hydropower potential (Schaefli et al. 2007). The SWAT model (Arnold et al. 1998) uses a simplified way of inserting climatic model inputs from the nearest station, i.e., for instance the closest to the centroid of the sub catchment is used for that sub catchment (Neitsch et al. 2005). This may lead to a certain inaccuracy due to spatial heterogeneity linked to meteriological data, especially in mountainous terrain. This can have significant implications on the runoff produced by the hydrological model used. Input uncertainty reduction is often a challenging task for hydrological models. Given the large uncertainity encountered when RCM are used as input data for SWAT, this study tested a number of RCMs at two different spatial resolutions by comparing simulated and observed runoff. Therefore the objective of this research is to assess the variability of the meteorological inputs generated from different RCMs for reproducing streamflow using SWAT hydrological model and performance evaluation of individual RCM.

\section{Study area}

The upper Rhone River is located in the south-western part of Switzerland; it originates in the Rhone glacier (Fette et al. 2007) and completes its alpine course in Lake Geneva. This segment is $167.5 \mathrm{~km}$ in length with a drainage basin of $5,220 \mathrm{~km}^{2}$. Approximately $14 \%$ of its surface is covered with glaciers (Meile et al. 2010) and $46 \%$ is covered with forest. The runoff behavior is characterized by two important regimes, namely the high flow period that occurs in the summer due to snow and ice melt, and the low flow period that occurs during the winter. The average observed precipitation of the basin is $1,435 \mathrm{~mm} /$ year. The upper Rhone is considered a seven order tributary; lower orders are illustrated in Fig. 1. Two major modifications were undertaken in 1930 and 1960 for flood protection for which $91 \%$ of its length was affected. This channeling reduced its original length from 424 to $251 \mathrm{~km}$ (Meile et al. 2010). In total 11 high head hydropower plants are located in the upper Rhone and most of them started functioning between 1951 and 1975. Therefore a shift of natural behavior has been observed since the construction of these 


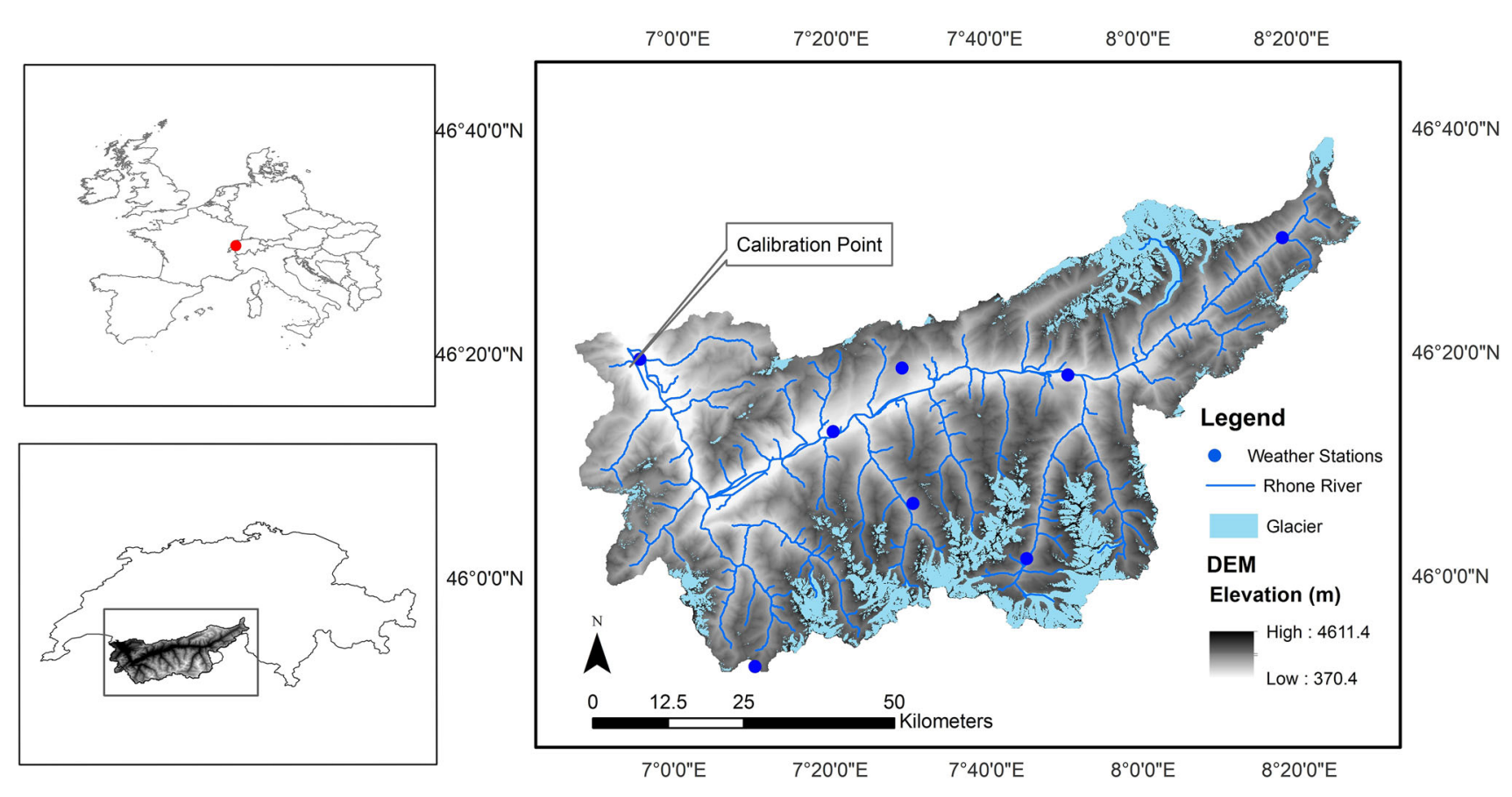

Fig. 1 Upper Rhone river catchment located in Valais (Switzerland)

dams due to both high flow and low flow periods because of controlled storage or release of water for hydropower operations. The complexity of the water transfer were therefore implemented in the model based on energy demand curve since the release of water has significant correlation with energy consumption. The river represents a very important source of water for the cantons of Valais and Vaud in Switzerland.

Elevation ranges from $400 \mathrm{~m}$ MSL at the floodplain part of the valley and 4,634 m MSL at the top of the Dufourspitze, the highest peak of Switzerland. Variability of precipitation is large due to its complex topography, the lowland is one of the most driest place in Switzerland with annual precipitation less than $600 \mathrm{~mm}$ and highest is at alpine part generally greater than 2,100 mm (Bordoy and Burlando 2012).

\section{Methodology}

Soil and water assessment tool

Soil and water assessment tool (Arnold et al. 1998) is a process-based distributed parameter watershed scale simulation model. It subdivides the watershed into numerous sub watersheds connected with the river network and smaller units called hydrological response units (HRU). Each HRU represents unique combination of land use, soil type and slope values. HRUs are non-spatially distributed assuming that there is no interaction or spatial dependency
(Neitsch et al. 2005). SWAT has been successfully applied in different parts of the world but relatively less often in snow and glacier dominated mountainous terrain. However, several studies have been performed or are ongoing to explore hydrological fluxes in mountain regions (Fontaine et al. 2002; Morid et al. 2004; Wang and Melesse 2005; Abbaspour et al. 2007; Ahl et al. 2008; Zhang et al. 2008; Debele et al. 2010; Pradhanang et al. 2011). The meteorological variables needed to run the model include precipitation, temperature, wind speed, solar radiation, and relative humidity on daily or sub daily time steps. SWAT simulates energy, hydrology, soil temperature, mass transport and land management at the sub basin and HRU levels. For this specific study, variables related to discharge and snow melt in mountainous terrain will be addressed; more detailed information about the other processes can be obtained from Neitsch et al. (2005). Reason of selection of SWAT model was because of its free availability along with prior application of the model for climate model performance test in various regions (Raneesh and Santosh 2011). Geographic and climatic data used for this study and their sources are listed in Table 1.

The hydrological routine of SWAT consists of discharge, snow melt, and both actual and potential evapotranspiration. The soil conservation services SCS curve number method from USDA was used for the surface runoff volume estimation. SWAT evaluates evapotranspiration through various approaches, such as FAO PenmanMonteith, Hargreaves, and Priestley-Taylor. For this study Penman-Monteith was found suitable based on the results 
Table 1 Data used and sources

\begin{tabular}{|c|c|c|c|}
\hline Data type & Data sources & Scale & Description \\
\hline DEM & Swiss-topo & $\begin{array}{l}\text { (Grid cell: } \\
25 \mathrm{~m} \times 25 \mathrm{~m})\end{array}$ & Elevation \\
\hline Land use & $\begin{array}{l}\text { Swiss Federal Statistical } \\
\text { Office }\end{array}$ & $\begin{array}{l}\text { (Grid cell: } \\
\quad 100 \mathrm{~m} \times 100 \mathrm{~m})\end{array}$ & Classified land use such as crop, urban forest water etc. \\
\hline Soil & $\begin{array}{l}\text { Swiss Federal Statistical } \\
\text { Office }\end{array}$ & $1: 200,000$ & $\begin{array}{l}\text { Classified soil and physical properties as sand silt clay bulk } \\
\text { density etc. }\end{array}$ \\
\hline Hydro network & Swiss-topo & $1: 25,000$ & River network-diversion \\
\hline River flow & FOEN & - & River discharge at daily time step \\
\hline Weather & MeteoSwiss & - & Precipitation temperature wind speed solar radiation \\
\hline $\begin{array}{l}\text { Hydropower } \\
\text { discharge }\end{array}$ & Alpiq, KW Mattmark & - & Inflow and outflow, lake level \\
\hline
\end{tabular}

obtained in the initial model performance before calibration. Since the hydrology of the Rhone watershed is driven by snow and glacier melt the we focused on the snow and glacier melt algorithms. For the detail description of the individual process of SWAT, readers are referred to the documentation (Neitsch et al. 2005).

Temperature is considered as driving factor for snow melt in the temperature index method (Hock 2003). The snow melt in SWAT is calculated as a linear function of the difference between the average snow pack-maximum air temperature and the base or threshold temperature for snow melt

$\mathrm{SNO}_{\mathrm{mlt}}=b_{\mathrm{mlt}} \cdot \mathrm{sno}_{\mathrm{cov}} \cdot\left[\frac{T_{\mathrm{snow}}+T_{\mathrm{mx}}}{2}-T_{\mathrm{mlt}}\right]$.

$\mathrm{SNO}_{\text {mlt }}$ is the amount of snow melt on a given day $(\mathrm{mm}$ $\left.\mathrm{H}_{2} \mathrm{O}\right), b_{\mathrm{mlt}}$ is the melt factor for the day $\left(\mathrm{mm} \mathrm{H}_{2} \mathrm{O} /\right.$ day- $\left.{ }^{\circ} \mathrm{C}\right)$, $\mathrm{sno}_{\text {cov }}$ is the fraction of HRU area covered by snow, $T_{\text {snow }}$ is the snow pack temperature on a given day $\left({ }^{\circ} \mathrm{C}\right), T_{\mathrm{mx}}$ maximum air temperature on a given day $\left({ }^{\circ} \mathrm{C}\right), T_{\text {mlt }}$ base temperature above which snow melt is allowed $\left({ }^{\circ} \mathrm{C}\right)$. The melt factor is allowed seasonal variation with maximum and minimum values occurring on summer and winter solstices

$$
\begin{aligned}
b_{\mathrm{mlt}}= & \left(\frac{b_{\mathrm{mlt} 6}+b_{\mathrm{mlt} 12}}{2}\right)+\left(\frac{b_{\mathrm{mlt} 6}-b_{\mathrm{mlt} 12}}{2}\right) \\
& \times \sin \left(\frac{2 \pi}{365}\left(d_{n}-81\right)\right)
\end{aligned}
$$

where, $b_{\text {mlt }}$ is the melt factor for the day $\left(\mathrm{mm} \mathrm{H}_{2} \mathrm{O} /\right.$ day- $\left.-{ }^{\circ} \mathrm{C}\right)$, $b_{\text {mlt6 }}$ is the melt factor for June $21\left(\mathrm{~mm} \mathrm{H}_{2} \mathrm{O} /\right.$ day- $\left.^{\circ} \mathrm{C}\right), b_{\text {mlt } 12}$ is the melt factor for December $21\left(\mathrm{~mm} \mathrm{H}_{2} \mathrm{O} / \mathrm{day}^{-}{ }^{\circ} \mathrm{C}\right), d_{n}$ is the day number of the year. This melt factors are parameterized for June (SMFMX) and for December (SMFMN) in the SWAT code. The glaciers are simulated as multi reservoir approach and melt rate is calculated as a function of daily air temperature (Rahman et al. 2013).

\section{PRUDENCE project}

The PRUDENCE project consists of numerous RCMs that were applied to Europe to assess a number of key climate variables, and to investigate eventual shifts of their mean values in a changing climate (Christensen et al. 2002). We analyzed four RCM-generated variables from DMI (Danish Meteorological Institute), SMHI (Swedish Meteorological and Hydrological Institute), METNO (Norwegian Meteorological Institute) and ICTP (International Center for Theoretical Physics, Italy). It is to be mentioned that several other RCMs output are available in the PRUDENCE web portal but we choose these four based on the availability of the input parameters. The input parameters are precipitation, temperature (daily mean and max). The inputs are: precipitation, minimum and maximum temperature, and wind speed. All the models used in this European project have been applied to two series of 30-year simulations, for the 1961-1990 period regarded as the control period, and for the last 30 years of the 21 st century 2071-2100, is considered as simulation period. All models have roughly the same spatial scale resolution, with grid sizes varying between $0.44^{\circ}$ and $0.5^{\circ}$, which correspond to approximately $50 \mathrm{~km}$. Moreover, some models have been tested at finer resolutions, with grid sizes as small as $0.22^{\circ}$ (SMHI and DMI) or even $0.11^{\circ}$ (DMI).

The models within the PRUDENCE project provide daily, monthly or seasonal outputs; in this study, only the daily outputs were used. Details regarding all the models used in this study are listed in Table 2.

Applications of RCMs are widely used for hydrological study and meteorological variable assessment with observation, e.g., Christensen and Christensen (2007), Maurer and Hidalgo (2008), Pal et al. (2004).

To assess the quality of the PRUDENCE simulations for the Rhone watershed, the daily outputs from the listed models for the four climatic variables of interest for this 
Table 2 Climate models and grid size

\begin{tabular}{llllll}
\hline Model & Acronym & Scale & $\begin{array}{l}\text { Number of grid } \\
\text { points in the } \\
\text { watershed }\end{array}$ & Variables & References \\
\hline DMI & HC1 & $50 \mathrm{~km}$ & 3 & $T_{\min }, T_{\max }$, Wind, Precip & (Christensen et al. 1996) \\
& F25 & $25 \mathrm{~km}$ & 15 & & \\
SMHI & HCCTL & $50 \mathrm{~km}$ & 3 & $T_{\min }, T_{\max }$, Wind, Precip & (Doscher et al. 2002) \\
& HCCTL_22 & $22 \mathrm{~km}$ & 17 & & \\
METNO & HADCN & $50 \mathrm{~km}$ & 3 & $T_{\min }, T_{\max }$, Wind, Precip & $\begin{array}{l}\text { (Christensen et al. 1996) } \\
\text { (Giorgi et al. 1993; Pal } \\
\text { ICTP }\end{array}$ \\
ref & $50 \mathrm{~km}$ & 3 & $T_{\min }, T_{\max }$, Precip & et al. 2000) \\
\hline
\end{tabular}

(a)

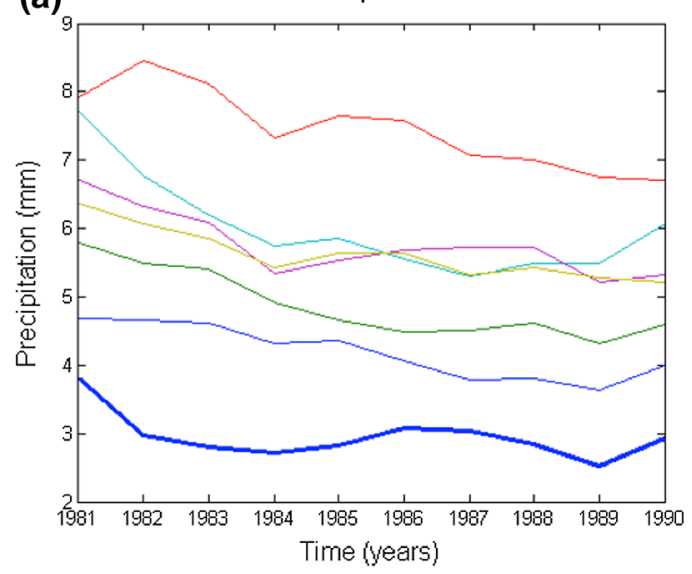

(c)

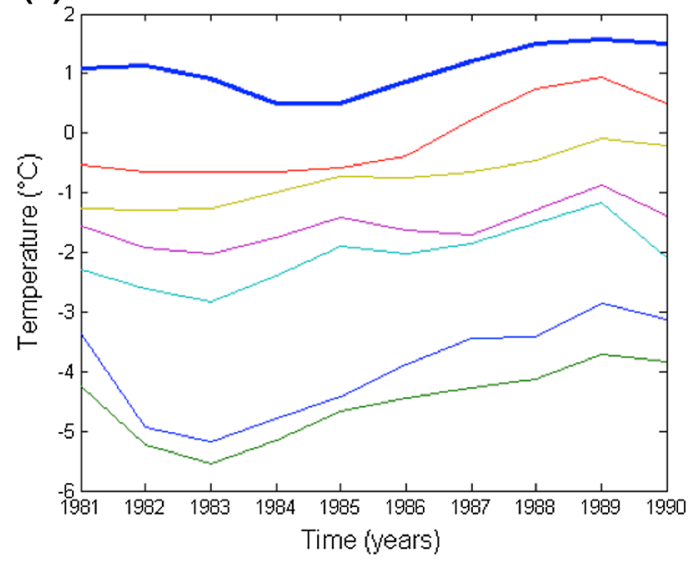

(b)

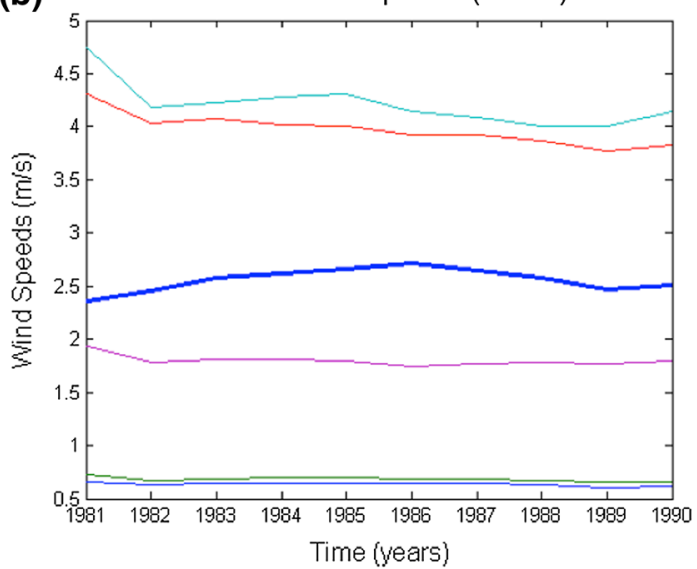

(d)

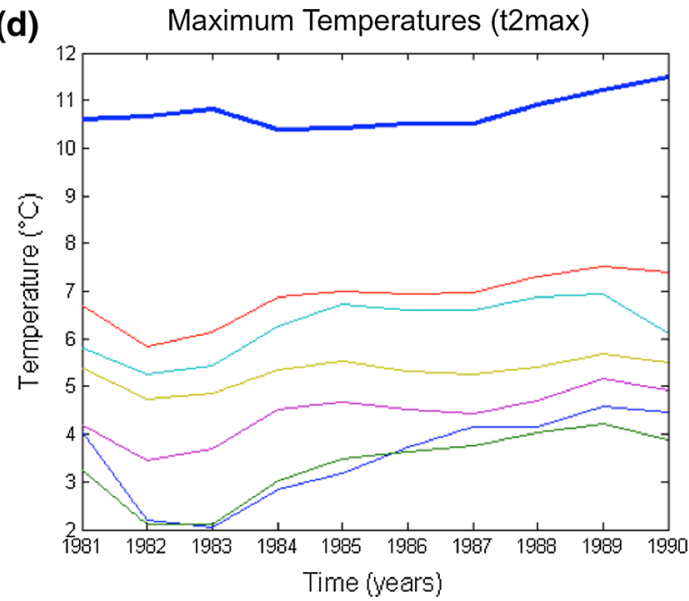

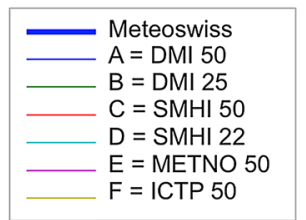

Fig. 2 Profiles for the 1981-1990 Periods of yearly means of PRUDENCE simulations and MeteoSwiss observations and of daily values of four climatic variables: precipitation (a), mean wind speeds (b), minimum (c) and maximum temperatures (d)

study $\left(T_{\min }, T_{\max }\right.$, precipitation and mean wind speed), were extracted for the model grid points that are located in the watershed (Fig. 2), for the control period (1961-1990). The extraction of meteorological variables were done specifying the geographic location of the watershed considering the min and max latitude and longitude (45.82 47.46; 5.3 7.68). All the conversion from NetCDF to time series has been done with MATLAB and the scripts are provided as supplementary document with this paper. The purpose is to assess the quality of these output variables regarding their orders of magnitude and their variability compared to observations provided by the eight MeteoSwiss meteorological stations located inside the study area. Knowing that the statistical records of observations are fully available only since 1981, the comparisons were merely investigated for the 10-year matching period from 1981 to 1990. For all the daily datasets (PRUDENCE outputs and meteorological observations), yearly means of all points located in the 
(a)

Precipitation

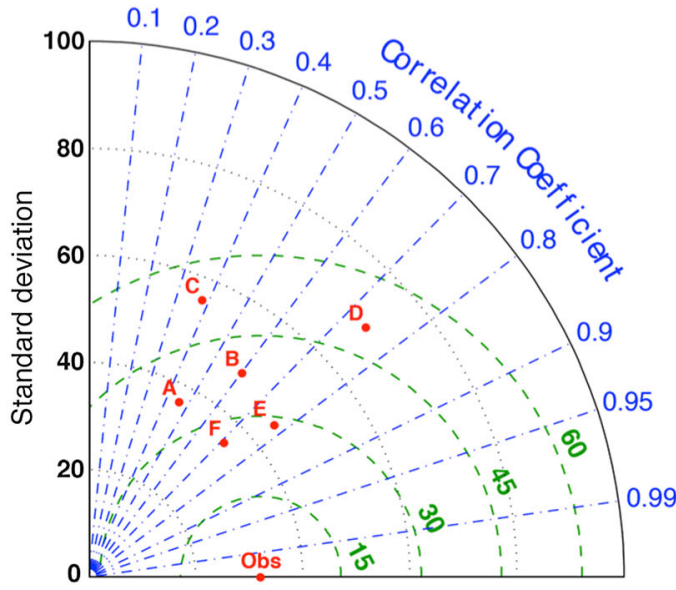

(c)

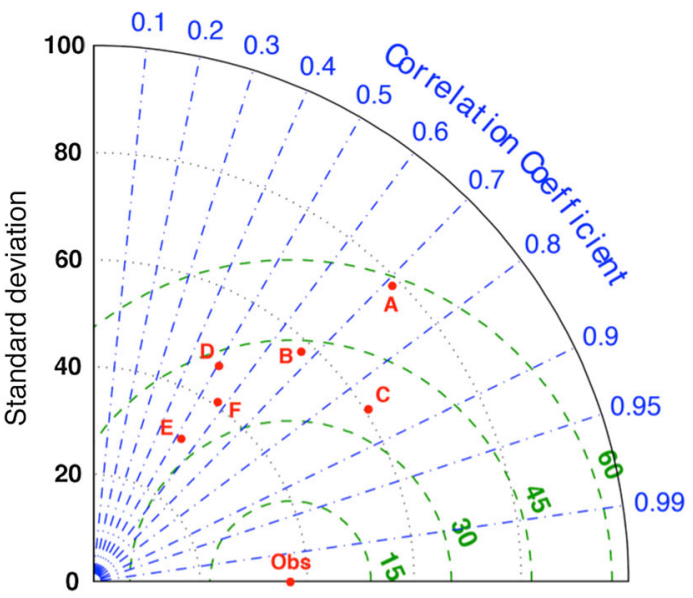

$A=$ DMI $50 \quad B=$ DMI $25 \quad C=$ SMHI 50

Fig. 3 Taylor diagrams plotting the MeteoSwiss data versus the simulation outputs for seven PRUDENCE models. Graphs show three axis, the $R^{2}$ correlation coefficients (in blue), the standard deviation ( $x$ and $y$ axis, in black) and the centered root-mean-square errors (in

watershed were calculated from 1981 to 1990 in order to compare the profiles of the different models. The correlation between the different simulated outputs from RCMs with the observed meteorological data using tailor diagrams (Taylor 2001) are represented by Fig. 3.

Hydrological model performance evaluation

Various statistics used for hydrological model performance analysis frequently employ Nash and Sutcliffe efficiency (NSE), mean square error (MSE) approaches. The percent bias (PBIAS) and root mean square error (RMSE) are also used for hydrological time series analysis. For this study we followed NSE, PBIAS and $R^{2}$ as model evaluation statistics (Moriasi et al. 2007). The model performance were (b)

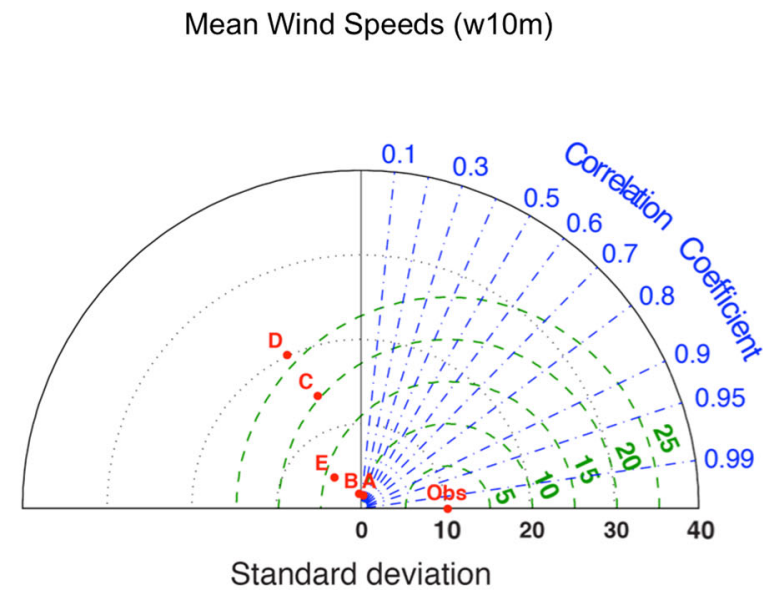

(d)

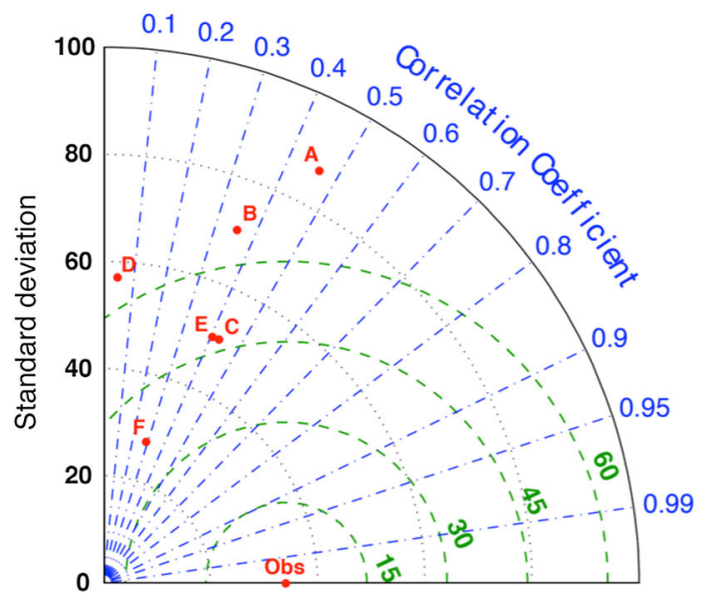

$D=S M H I 22 \quad E=$ METNO $50 \quad F=$ ICTP 50

green). Observations are intersecting the $x$-axis. a Precipitation, b mean wind speeds at $10 \mathrm{~m}$ elevation, c minimum, $\mathbf{d}$ maximum temperatures are given

considered satisfactory if NSE $>0.5$ and PBIAS $= \pm 25 \%$ and $R^{2}>0.6$

$\mathrm{NSE}=1-\frac{\sum_{t=1}^{T}\left(Q_{m, t}-Q_{s, t}\right)^{2}}{\sum_{t=1}^{T}\left(Q_{m, t}-\bar{Q}_{m}\right)^{2}}$

PBIAS $=\left[\frac{\sum_{t=1}^{T}\left(Q_{s, t}-Q_{m, t}\right)}{\sum_{t=1}^{T} Q_{m, t}}\right] \times 100$

$R^{2}=\left[\frac{\sum_{t=1}^{T}\left(Q_{m, t}-\bar{Q}_{m}\right)\left(Q_{s, t}-\bar{Q}_{s}\right)}{\sum_{t=1}^{T}\left[\left(Q_{m, t} \bar{Q}_{m}\right)^{2}\right]^{0.5} \sum_{t=1}^{T}\left[\left(Q_{s, t} \bar{Q}_{s}\right)^{2}\right]^{0.5}}\right]^{2}$.

NSE indicates the strength of the relationship of observed and simulated values where $Q_{m, t}$ is the observed 
data value at time $t$ and $Q_{s, t}$ is the simulated data value at time $t$. NSE values lie between $-\infty$ to +1 , (Nash and Sutcliffe 1970). Values close to +1 indicates the better model performance.

The PBIAS indicates the average tendency of the simulated data to be larger or smaller than their observed values. According to Gupta et al. (1999), the PBIAS can be utilized as an indicator of under- or over-estimation. Negative PBIAS indicates the underestimation of modelgenerated values with respect to the measured values. The square of Pearson's product moment correlation is indicated by $R^{2}$ which represent the proportions of total variance of the measured data that can be explained by the simulated data. Higher values of $R^{2}$ for simulated data close to 1 represent better model performance.

\section{Results and discussion}

This part of the paper contains five sections. In the first section meteorological variables were represented with the observed variables and in the second section comparison with the observed value were plotted with tailor diagram. In the third section, the calibration of the hydrological model based on the local data and the list of parameters responsible were described. In the fourth section, the performance test of climatic variables for reproducing runoff is represented. Finally the impact of grid resolution of reproducing the observed hydrograph is assessed in the fifth section.

\section{Profiles analysis of SWAT input variables}

The results obtained for the comparison between the simulated and observed values for the four climate variables for the watershed are shown in Fig. 2. All graphs plot the yearly mean values from 1981 to 1990 for the various PRUDENCE models and for the meteorological observations (bold lines). Apart from the wind speeds, the graphs indicate that all PRUDENCE models either overestimate or underestimate the observed values. For precipitation (Fig. 2a), the PRUDENCE models overestimate the observed precipitation amounts. The two DMI simulations provided the best results. The grid resolution seems to have less influence on the effectiveness of the outputs, as the $\mathrm{HC} 1$ run seem to be better matching observations than the F25 runs. Overall, simulations and observations seem to indicate a slight decrease of precipitation in the Rhone watershed.

For the two temperature graphs (Fig. 2c, d), the SMHI HCCTL outputs are the closest to the meteorological observations. Nevertheless, although they differ in their orders of magnitude, all PRUDENCE runs have similar trends for both the minimum and maximum temperatures. The DMI values are very close to each other (especially for the $T_{2 \max }$ values), but rather far away from the observations. Trends can be observed on both temperature graphs for the 1981-1990 decade: Fig. 2c shows an increase of the minimum temperatures, whereas the maximum temperatures seem to be gently decreasing. These trends need to be investigated for longer periods before making any concluding remarks regarding the climate of Rhone watershed. The wind graph (Fig. 2b) reveals little variability in the mean wind speeds during the 1981-1990 periods for all datasets. This is particularly the case for the two DMI runs, which show a constant close to zero wind speed. The METNO outputs provide values just below $2 \mathrm{~m} / \mathrm{s}$ that are the closest to the observations.

Taylor diagrams of SWAT input variables

After having assessed the orders of magnitude of the simulated variables compared to the meteorological observations, one needs to investigate the correlation between datasets. These are shown in Fig. 3 in the form of Taylor diagrams (Taylor 2001) for each of the four climatic variables. These diagrams are very useful when assessing the performance of many models as they graphically summarize their patterns into a single plot and allow comparing them to the observed data. The models performances are expressed in terms of their correlation, their centered RMS difference and their standard deviations compared to observations. These diagrams have been widely used in the past to assess the quality of various simulated outputs (Maurer et al. 2002). The radial coordinate gives the standard deviation and the angular coordinate provides the correlation with the observations. Furthermore, the distance between the observation point and the models' point is proportional to the RMSE model error.

Precipitation (4a): coefficients values are scaled from 0.4 to 0.8 , with the SMHI HCCTL_22, the METNO and the ICTP models having the highest coefficients. However, when analyzing the standard deviations, Fig. 3a indicates that METNO and ICTP provide the patterns that are the most similar to the observations. This graph indicates that although the DMI precipitation outputs are of the same order of magnitude as the observations (Fig. 2a), other models can provide better performance in terms of their correlations and patterns. Concerning wind speeds (Fig. 3b): the graph indicates that correlations are very low, with values even being negative. The variability between all datasets is similar and close to zero. Minimum temperatures (Fig. 3c): the SMHI HCCTL model seems to provide the best results, with coefficients reaching 0.85 , but with a more important variability compared to the observations. Moreover, as plotted in Fig. 2c, outputs are of 
similar values than the observed, indicating that SMHI HCCTL is providing satisfying results for minimum temperatures. All other models have coefficients that are between 0.4 and 0.7. Maximum temperatures (Fig. 3d): coefficients are lower than for the minimum temperatures as they are all below 0.5. Furthermore, except for the ICTP, standard deviations for simulations are higher than the observation data. One important signature of DMI can be noticed that the correlation is highest compared to other RCMs.

Hydrological model calibration and validation

The Hydrological model calibrations were done on daily simulations in order to satisfy the statistical performance listed in Eqs. (3), (4) and (5). Comparing pre- and post- calibration (Fig. 4a, b) and the major problems identified were the overestimation of peak flow, the underestimation of low flow and the influence of secondary peaks. The sensitivity test was done using parasol (van Griensven et al. 2006), a built in sensitivity technique embedded in SWAT. The parameter adjustments were done by manual calibration. We tried to calibrate the model with a lower number of parameters in order to avoid the over parameterization problem. Both high flow and low flow parameters were tuned based on expert knowledge and existing literature (Klok et al. 2001). The surface water lag coefficient (SURLAG) was set to 1 instead of the default value of 4 considering the steep gradient of the mountainous terrain. The melt factor for June (SMFMX) was adjusted to 5.9 from the default value of 4.5. Similarly melt factor for December (SMFMN) was adjusted to 4.6. The snow
Fig. 4 Observed and simulated relationship based on station data at the most downstream point of the watershed a before calibration, b after calibration, c validation
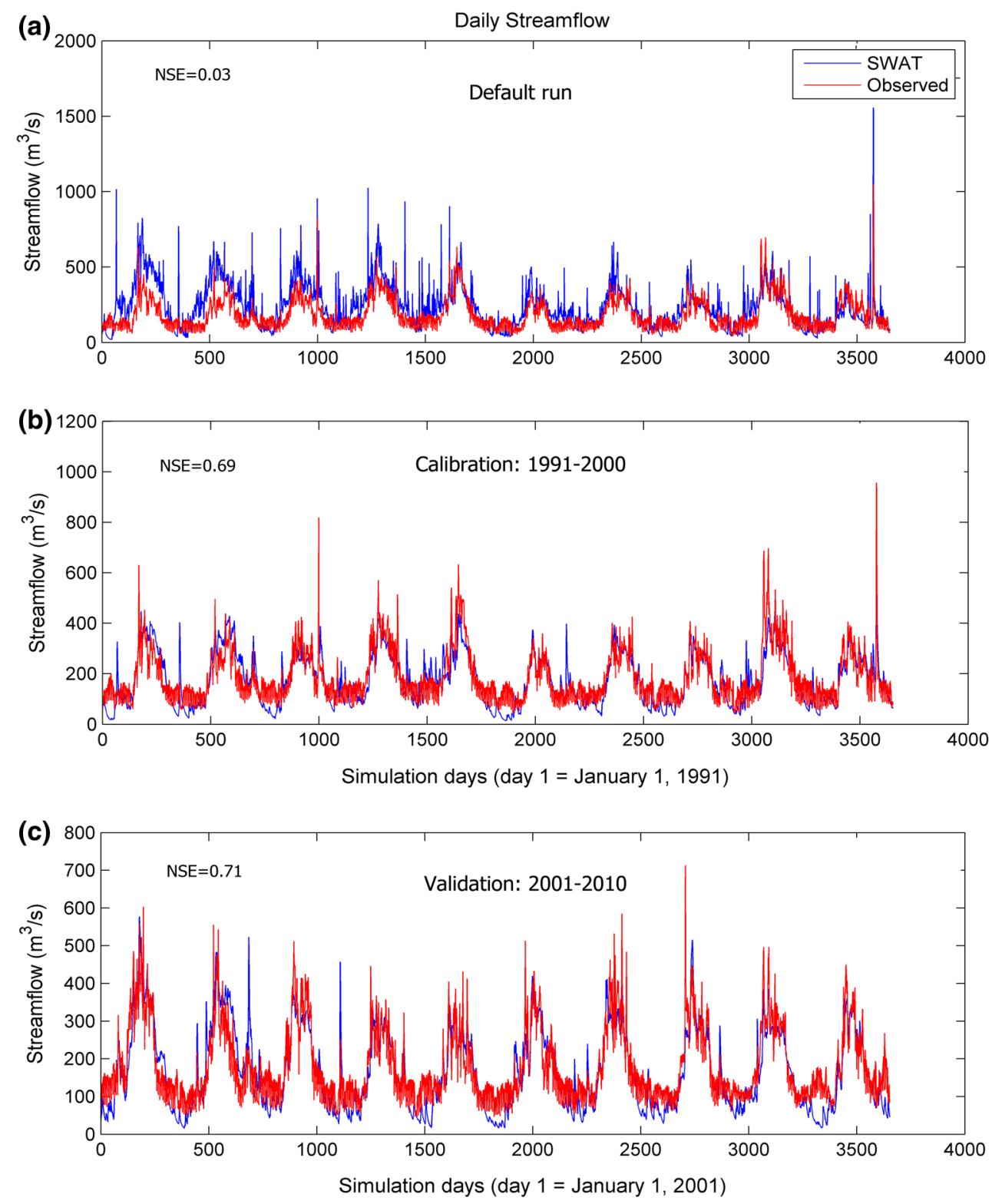
parameter lag factor (TIMP) was adjusted to 0.572 within its range of 0 and 1 . The threshold temperature for snow melt was adjusted to the value of 4.5 The overall precipitation lapse rate value was kept as $10 \mathrm{~mm} / \mathrm{km}$, and temperature lapse rate was tuned to $-3.920{ }^{\circ} \mathrm{C} / \mathrm{km}$ following the results from the literature (Klok et al. 2001). Among the nine parameters TIMP was found most sensitive for model performance statistics because it is directly related to the melt process. Along with TIMP other snow related parameters like initial snow content were assigned as $300 \mathrm{~mm}$ as the simulation starts from January. We used 30 years measured daily discharges for our study at the downstream points of the watershed (Porte du seux) starting from 1981 to 2010 . We split the time line for three slices, first 10 years for warming up the model, 10 years (1991-2000) for calibration and 10 years (2001-2010) was used for validation of the model illustrated in Fig. 4.

\section{Hydrograph generated from different RCMs}

We compared the model-generated hydrographs with the observed hydrographs based on high flow period, low flow period, occurrence of high flow period and duration of high flow period. In Fig. 5 (blue colored) the bell-shaped hydrograph illustrates the monthly average discharge obtained from the observed data and the red the local station data. The high flow occurs in the summer time and the low flow period in winter time. The flow periods are highly correlated with the temperature and precipitation of the study area. Because the study area is located at a high altitude during the winter period it is covered with snow and ice, the snow accumulation process occurs during the winter therefore the flow is low compared with summer. Considering the shape of the hydrograph, only with the input from DMI could we produce a similar pattern, although there is a systematic over estimation during the high flow period, the peak flow is also overestimated. For instance, naturally,

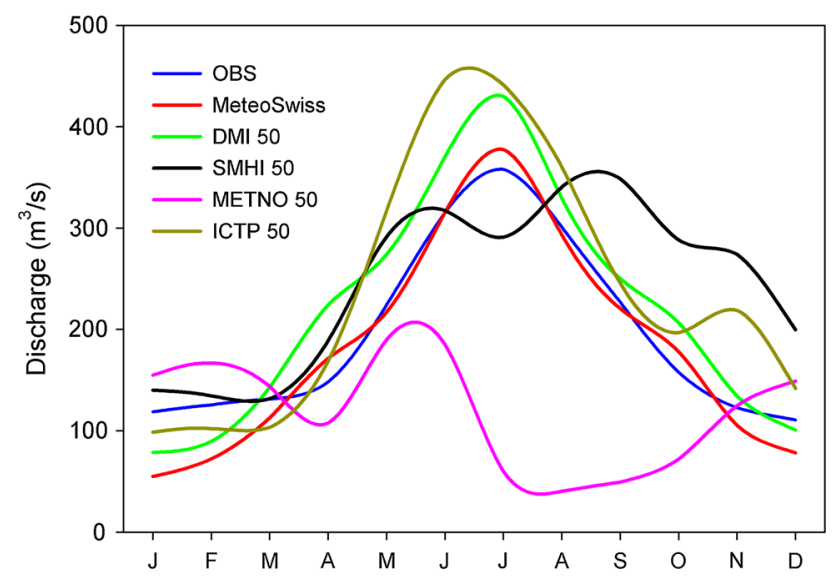

Fig. 5 Monthly average hydrograph and outputs with RCMs average peak flow occurs around $350 \mathrm{~m}^{3} / \mathrm{s}$, whereas the DMI-generated hydrograph, at $450 \mathrm{~m}^{3} / \mathrm{s}$. None of the other climatic model generated output could reproduce a similar hydrograph pattern. Besides the DMI model, the output from ICTP has a similar pattern, but the peak flow is again highly over estimated; moreover there is an influence of the secondary peak during the recession limb of the hydrograph. The hydrograph generated from both SMHI and METNO models has a different shape and does not reproduce the similar time of occurrence of peak flow; the duration of high flow also does not match the natural flow. The hydrograph generated with the METNO model present a pattern that has less similarity with the natural flow regime.

Usually the discharge pattern of Switzerland is rather like a bell-shaped curve, which physically means that high flow periods are occurring during the summer and the low flow periods are occurring during the winter. This is due to the melting of snow and ice during summer. We therefore see, based on the discharge curves, that only the DMI output could produce a similar curve despite a sharper drop in the recession limb of the hydrograph.

\section{Impact of grid resolution}

In total three grid points fall within the watershed from the $50 \times 50 \mathrm{~km}^{2}$ grid of DMI as well as in the SMHI model (Fig. 6). Whereas a total of 15 points fall within the $25 \times 25 \mathrm{~km}^{2}$ grid from DMI and 17 points from SMHI. The hydrograph generated from $25 \times 25 \mathrm{~km}^{2}$ and $50 \times 50 \mathrm{~km}^{2}$ grids exhibit similar peak flows, but in the low flow period $25 \times 25 \mathrm{~km}^{2}$ grids provided slightly improved statistical values, when comparing the observed hydrograph. For the DMI output, the main difference between the $50 \times 50$ and $25 \times 25 \mathrm{~km}^{2}$ grids is visible at the start of the high flow period (February to May). Whereas in the SMHI $22 \times 22 \mathrm{~km}^{2}$ grid the values better reproduce the results during the peak flow period. The duration of high flow period was highly overestimated for both grid sizes when compared to the observed value. For instance the observed peak flow reduction process starts in July-August whereas the model generated discharge still continues until September-October. Compared to the 50 and $22 \mathrm{~km}$ grid point resolutions, the $22 \mathrm{~km}$ grid produces better statistics (Table 3), changing the hydrograph to a more skewed shape.

Statistical performance

Streamflow simulation based on the model generated variables provided little correlation with the observed value. When considering the models' statistical performance [based on the Eqs. (3) to (5)], of the four models, 
Fig. 6 Grid points from different PRUDENCE models that were used in this study. a Points of models at $50 \mathrm{~km}$ grid size, b points at $25 \mathrm{~km}$

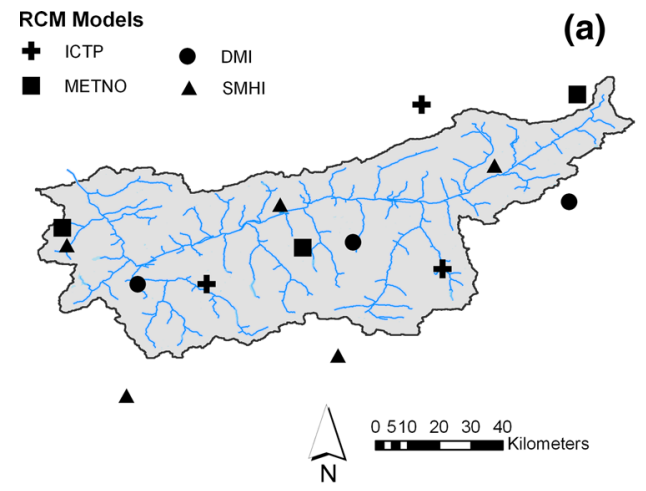

(b)

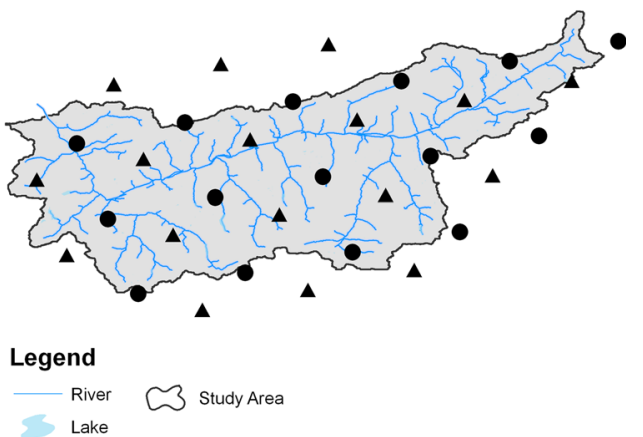

Table 3 Statistical performance of individual RCMs and local stations

\begin{tabular}{lllr}
\hline Data sources & NSE & $R^{2}$ & PBIAS \\
\hline MeteoSwiss & 0.71 & 0.81 & -5.27 \\
DMI 25 & 0.37 & 0.63 & -10.87 \\
DMI 50 & 0.22 & 0.59 & -12.52 \\
SMHI 22 & -0.47 & 0.25 & -22.46 \\
SMHI 50 & -0.9 & 0.14 & -25.82 \\
METNO 50 & -2.4 & 0.012 & 44.12 \\
ICTP 50 & -1.2 & 0.35 & 21.46 \\
\hline
\end{tabular}

the DMI with the higher resolution grid shows better results than the other models. Instead of using independent model results, ensemble multi-model means can also be used. However for performance analysis of specific application as discharge or return periods, the single model output can be more adequate than a multi-model ensemble mean. Similar results were reported by (Salzmann and Mearns 2012) that ensemble means do not necessarily provide better performance than single models. Therefore, after the sensitivity test of the RCMs with the observed data, it is important to apply an adjustment factor, e.g., the lapse rate for precipitation or temperature based on the physical characteristics of the watershed. These adjustment factors could be spatial or temporal, for spatial characteristics it can be elevation and slope of the region. For instance, Pepin and Losleben (2002) proposed the adjustment for the Colorado River basin with temporal adjustment, applying a monthly average lapse rate. NSE is often considered as the most significant correlation between the simulated and observed relationship. However, the volume estimations can be establish with PBIAS, it is always recommended that PBIAS should be within negative and positive value near around 10 (Moriasi et al. 2007). Negative and positive values of PBIAS are based on overestimation and under estimation of simulated relationship as we can see from the result of DMI and METNO.
Discussion

The performance evaluation of global and RCM generated variables are analyzed in various ongoing studies, among the recent literatures, Jiang et al. (2013) examined the precipitation generated from $16 \mathrm{GCMs}$ and $10 \mathrm{RCMs}$ for four US cities and found the variability is quite significant. Their finding suggests current GCMs/RCMs tend to simulate longer storm duration and lower storm intensity comparing to observed records. Also, most GCMs/RCMs failed to produce the high-intensity summer storms when they are not bias corrected. Similar to our objective Hwang et al. (2013) focused streamflow response to dynamicallydownscaled regional reanalysis data in central Tampa Bay region of Florida utilizing a hydrological model, where they noticed the reanalysis data provided better hydrological model generated streamflow then the raw data obtained from RCMs. Therefore, there is a need to focus on reanalysis techniques which in terms emphasizes the need of bias correction of meteorological variables. Not only for streamflow simulation, other variables like evapotranspiration (Obeysekera 2013) can also be an important element that often utilize RCMs for future forecast using hydrological models.

The bias correction algorithms are various types, among them statistical approach like quantile mapping, histogram equalization, and rank matching are notable. New techniques are immerging along with the recognized methods however they are often controversial while applying in a set of RCMs. A realistic representation is yet to be a challenge due to our limited knowledge in the atmospheric physics and due to involvement of large number of variables. Most often bias corrections are done when the climate model generated outputs are systematically underestimated or over estimated. Therefore, there is a certain need to improve our understanding on bias correction technique not only spatial analysis but also with time series, more importantly seasonal basis.

Considering the performance evaluation criteria based on tailor diagram (Fig. 3) in connection with the 

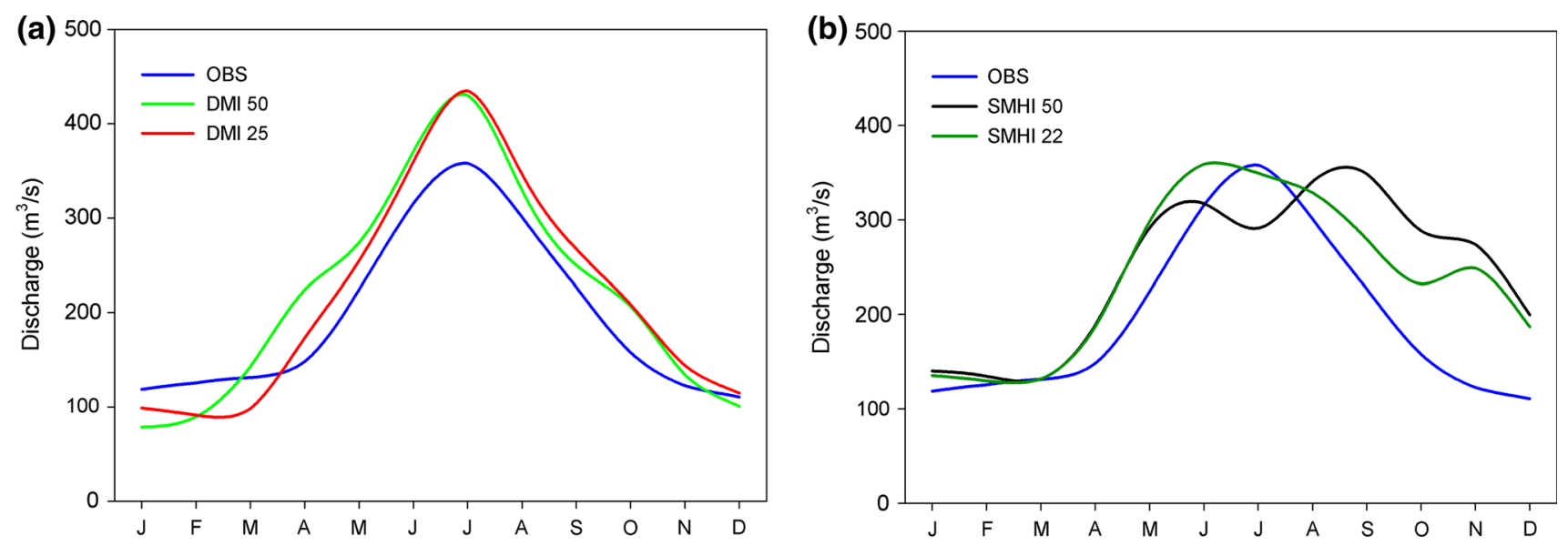

Fig. 7 Hydrograph comparing the results obtained with a outputs from DMI, b outputs of SMHI

streamflow (Fig. 5) it is depicted that there is no strong harmonization of independent model generated variables with observation records. Especially the profile analysis illustration of maximum temperature (Fig. 3d) DMI has highest correlation value $(0.475)$ whereas SMHI has lowest (0.01). This is reflected in the hydrograph because the melt rate of snow and glaciers are significantly correlated with daily maximum temperature denoted in the denominator of the Eq. (1). Moreover, glacier melt uses the similar approach as temperature index, where melt rate is linear function of daily maximum air temperature, hence a significant percentage of streamflow is generated from glacier melt it is apparent that the daily maximum temperature will affect the model performance. It is visible that DMI generated variables provided streamflow with an overestimation of the entire period which is quite systematic. Our assumption is that this systematic overestimation can be resolved using the temperature lapse rate. Similarly the lapse rate of precipitation can also help providing significant improvement in bias correction techniques.

\section{Conclusions}

This study compared the gridded meteorological variables obtained from RCM outputs along with the local stations. As the hydrological models are driven by meteorological inputs such as precipitation and temperature we analyzed different climate models as input of the hydrological model. The variability found was quite significant compared to the local station which influences the model performance. The hydrological model (SWAT) was used for simulating discharge based on the climate inputs for reproducing runoff in the upper Rhone River watershed. At first we built the hydrological model based on the local station data and calibrated the model, later the meteorological inputs were replaced and simulated each time. We considered the hydrograph analysis both visually and statistically. Considerations were made for high flow period, low flow period, time of flow occurrence and duration of high flow period. We found temperature driven variables are more sensitive in the high altitude catchment as the melt processes are highly linked with the variability of temperature ( $\min$ and $\max$ ). Among the set of climate models driven hydrograph, the DMI model generated variables were able to reproduce similar patterns of high flows. Despite generating a similar pattern of hydrograph shape, the simulated hydrograph underestimated low flow and overestimated high flow. Apparently, a set of RCM driven variables could not produce similar pattern of hydrograph. Some of the climate models reproduced hydrographs with secondary peaks which have not been observed in reality. We analyzed 50 and $25 \mathrm{~km}$ grid resolutions for the DMI model and the 50 and $22 \mathrm{~km}$ scales for the SMHI model. The output from both resolutions reproduced similar patterns, but finer grids provided better performance with respect to the shape of the hydrograph and overall statistical performance (Fig. 7). Therefore, our conclusion is to test the acceptability of the RCM-generated variables before applying them to the decision making level especially for mountainous watershed emphasizing the temperature as a driving variable for bias correction studies. Our recommendation would be to use a correction factor for meteorological variables (ex. lapse rate along with elevation) before implementing them in complex terrain for impact modeling.

Acknowledgments Most of the work was done during the $\mathrm{PhD}$ program fellowship at University of Geneva with funding from EU FP 7 project ACQWA [Assessing climate change impact on water quality and quantity] under Grant Nr. 212250. We wish to thank the Federal Office of Meteorology and Climatology MeteoSwiss for providing the daily precipitation, maximum and minimum temperatures, and wind 
speed required for building the hydrological model. The geographic data was obtained from Federal Office for the Environment (FOEN). We also acknowledge equally the ALPIQ and KW-MATTMARK hydropower companies for providing discharge and lake level data. The coordinates of the intake points were collected from the hydropower consulting engineers E-dric (www.e-dric.ch).

\section{References}

Abbaspour KC, Yang J, Maximov I, Siber R, Bogner K, Mieleitner J, Zobrist J, Srinivasan R (2007) Modelling hydrology and water quality in the pre-ailpine/alpine Thur watershed using SWAT. J Hydrol 333(2-4):413-430

Ahl RS, Woods SW, Zuuring HR (2008) Hydrologic calibration and validation of SWAT in a snow-dominated rocky mountain watershed, Montana, USA. J Am Water Resour Assoc 44(6):1411-1430. doi:10.1111/j.1752-1688.2008.00233.x

Arnold JG, Srinivasan R, Muttiah RS, Williams JR (1998) Large area hydrologic modeling and assessment, part 1: model development. JAWRA 34(1):73-89. doi:10.1111/j.1752-1688.1998. tb05961.x

Beniston M (2010) Impacts of climatic change on water and associated economic activities in the Swiss Alps. J Hydrol. doi:10.1016/j.jhydrol.2010.06.046

Beniston M, Goyette S (2007) Changes in variability and persistence of climate in Switzerland: exploring 20th century observations and 21 st century simulations. Glob Planet Change 57(1-2):1-15. doi:10.1016/j.gloplacha.2006.11.004

Beniston M, Uhlmann B, Goyettea S, Lopez-Morenob JI (2011) Will snow-abundant winters still exist in the Swiss Alps in an enhanced greenhouse climate? Int J Climatol 31(9):1257-1263. doi:10.1002/joc. 2151

Bordoy R, Burlando P (2012) Bias correction of regional climate model simulations in a region of complex orography. J Appl Meteorol Climatol 52(1):82-101. doi:10.1175/jamc-d-11-0149.1

Bosshard T, Kotlarski S, Ewen T, Schaer C (2011) Spectral representation of the annual cycle in the climate change signal. Hydrol Earth Syst Sci 15(9):2777-2788. doi:10.5194/hess-152777-2011

Chen H, Xu C-Y, Guo S (2012) Comparison and evaluation of multiple GCMs, statistical downscaling and hydrological models in the study of climate change impacts on runoff. J Hydrol 434-435:36-45. doi:10.1016/j.jhydrol.2012.02.040

Christensen JH, Christensen OB (2007) A summary of the PRUDENCE model projections of changes in European climate by the end of this century. Clim Change 81:7-30

Christensen JH, Christensen OB, Lopez P, van Meijgaard E, Botzet M (1996) The HIRHAM4 regional atmospheric climate model. DMI Technical Report 96-4. DMI, Copenhagen Ø

Christensen JH, Carter TR, Giorgi F (2002) PRUDENCE employs new methods to assess European climate change. EOS (American Geophysical Union Newsletter) 83:13

Debele B, Srinivasan R, Gosain AK (2010) Comparison of processbased and temperature-index snowmelt modeling in SWAT. Water Resour Manag 24(6):1065-1088

Doscher R, Willén U, Jones C, Rutgersson A, Meier HM, Hansson U, Graham LP (2002) The development of the regional coupled ocean-atmosphere model RCAO. Boreal Environ Res 7(3): 183-192

Fette M, Weber C, Peter A, Wehrli B (2007) Hydropower production and river rehabilitation: a case study on an alpine river. Environ Model Assess 12(4):257-267

Fontaine TA, Cruickshank TS, Arnold JG, Hotchkiss RH (2002) Development of a snowfall-snowmelt routine for mountainous terrain for the soil water assessment tool (SWAT). J Hydrol 262(1-4):209-223

Giorgi F, Marinucci MR, Bates GT (1993) Development of a secondgeneration regional climate model (RegCM2). Part I: Boundarylayer and radiative transfer processes. Mon Weather Rev 121(10):2794-2813

Graham LP, Andreasson J, Carlsson B (2007) Assessing climate change impacts on hydrology from an ensemble of regional climate models, model scales and linking methods: a case study on the Lule River basin. Clim Change 81:293-307. doi:10.1007/ s10584-006-9215-2

Gupta HV, Sorooshian S, Yapo PO (1999) Status of automatic calibration for hydrologic models: comparison with multilevel expert calibration. J Hydrol Eng 4(2):135-143. doi:10.1061/ (asce)1084-0699(1999)4:2(135)

Hock R (2003) Temperature index melt modelling in mountain areas. J Hydrol 282(1-4):104-115. doi:10.1016/s0022-1694(03)00257-9

Hwang S, Graham W, Adams A, Geurink J (2013) Assessment of the utility of dynamically-downscaled regional reanalysis data to predict streamflow in west central Florida using an integrated hydrologic model. Reg Environ Change 1-12. doi:10.1007/ s10113-013-0406-x

Jiang P, Gautam MR, Zhu J, Yu Z (2013) How well do the GCMs/ RCMs capture the multi-scale temporal variability of precipitation in the Southwestern United States? J Hydrol 479:75-85. doi:10.1016/j.jhydrol.2012.11.041

Klok EJ, Jasper K, Roelofsma KP, Gurtz J, Badoux A (2001) Distributed hydrological modelling of a heavily glaciated Alpine river basin. Hydrol Sci J 46(4):553-570

Leander R, Buishand TA (2007) Resampling of regional climate model output for the simulation of extreme river flows. J Hydrol 332(3-4):487-496. doi:10.1016/j.jhydrol.2006.08.006

Lenderink G, Buishand A, van Deursen W (2007) Estimates of future discharges of the river Rhine using two scenario methodologies: direct versus delta approach. Hydrol Earth Syst Sci 11(3):1143-1159

Lettenmaier DP, Wood AW, Palmer RN, Wood EF, Stakhiv EZ (1999) Water resources implications of global warming: a US regional perspective. Clim Change 43(3):537-579. doi:10.1023/ a: 1005448007910

Liechti TC, Matos JP, Boillat J-L, Schleiss AJ (2012) Comparison and evaluation of satellite derived precipitation products for hydrological modeling of the Zambezi River Basin. Hydrol Earth Syst Sci. doi:10.5194/hess-16-489-2012

Liu W, Cai T, Fu G, Zhang A, Liu C, Yu H (2013) The streamflow trend in Tangwang River basin in northeast China and its difference response to climate and land use change in sub-basins. Environ Earth Sci 69(1):51-62

Masih I, Maskey S, Uhlenbrook S, Smakhtin V (2011) Assessing the impact of areal precipitation input on streamflow simulations using the SWAT modell. J Am Water Resour Assoc 47(1):179-195. doi:10.1111/j.1752-1688.2010.00502.x

Maurer EP, Hidalgo HG (2008) Utility of daily vs. monthly largescale climate data: an intercomparison of two statistical downscaling methods. Hydrol Earth Syst Sci 12(2):551-563

Maurer E, Wood A, Adam J, Lettenmaier D, Nijssen B (2002) A long-term hydrologically based dataset of land surface fluxes and states for the conterminous United States. J Clim $15: 3237-3251$

Meile T, Boillat JL, Schleiss A (2010) Hydropeaking indicators for characterization of the Upper-Rhone River in Switzerland. Aquat Sci 73(1):171-182

Moriasi DN, Arnold JG, Van Liew MW, Bingner RL, Harmel RD, Veith TL (2007) Model evaluation guidelines for systematic quantification of accuracy in watershed simulations. Trans Asabe 50(3):885-900 
Morid SG, Gosain AK, Keshari AK (2004) Response of different snowmelt algorithms to synthesized climatic data for runoff simulation. J Earth Space Phys 30(1):1-4

Murphy J (1999) An evaluation of statistical and dynamical techniques for downscaling local climate. J Clim 12(8):2256-2284. doi:10.1175/1520-0442(1999)012<2256:aeo $\operatorname{sad}>2.0 . \mathrm{co} ; 2$

Nash JE, Sutcliffe JV (1970) River flow forecasting through conceptual models part I: a discussion of principles. J Hydrol 10(3):282-290. doi:10.1016/0022-1694(70)90255-6

Neitsch SL, Arnold JG, Kiniry J, Williams JR (2005) Soil and water assessment tool theoretical documentation. USDA Agricultural Research Service and TexasA \& MBlackland Research Center, Temple, Texas

Obeysekera J (2013) Validating climate models for computing evapotranspiration in hydrologic studies: how relevant are climate model simulations over Florida? Reg Environ Change 1-10. doi:10.1007/s10113-013-0411-0

Pal JS, Small EE, Eltahir EA (2000) Simulation of regional-scale water and energy budgets: representation of subgrid cloud and precipitation processes within RegCM. J Geophys Res Atmos (1984-2012) 105(D24):29579-29594

Pal JS, Giorgi F, Bi X (2004) Consistency of recent European summer precipitation trends and extremes with future regional climate projections. Geophys Res Lett 31(13)

Pavlik D, Söhl D, Pluntke T, Mykhnovych A, Bernhofer C (2012) Dynamic downscaling of global climate projections for Eastern Europe with a horizontal resolution of $7 \mathrm{~km}$. Environ Earth Sci 65(5):1475-1482

Pepin N, Losleben M (2002) Climate change in the Colorado Rocky Mountains: free air versus surface temperature trends. Int $\mathrm{J}$ Climatol 22(3):311-329. doi:10.1002/joc.740

Pradhanang SM, Anandhi A, Mukundan R, Zion MS, Pierson DC, Schneiderman EM, Matonse A, Frei A (2011) Application of SWAT model to assess snowpack development and streamflow in the Cannonsville watershed, New York, USA. Hydrological Processes n/a-n/a. doi:10.1002/hyp.8171
Rahman K, Maringanti C, Beniston M, Widmer F, Abbaspour K, Lehmann A (2013) Streamflow modeling in a highly managed mountainous glacier watershed using SWAT: the upper Rhone River watershed case in Switzerland. Water Resour Manag 27(2):323-339. doi:10.1007/s11269-012-0188-9

Raneesh KY, Santosh GT (2011) A study on the impact of climate change on streamflow at the watershed scale in the humid tropics. Hydrol Sci J 56(6):946-965

Salzmann N, Mearns LO (2012) Assessing the performance of multiple regional climate model simulations for seasonal mountain snow in the upper Colorado River Basin. J Hydrometeorol 13(2):539-556. doi:10.1175/2011jhm1371.1

Schaefli B, Hingray B, Musy A (2007) Climate change and hydropower production in the Swiss Alps: quantification of potential impacts and related modelling uncertainties. Hydrol Earth Syst Sci 11(3):1191-1205

Schoetter R, Hoffmann P, Rechid D, Schluenzen KH (2012) Evaluation and bias correction of regional climate model results using model evaluation measures. J Appl Meteorol Climatol 51(9):1670-1684. doi:10.1175/jamc-d-11-0161.1

Taylor KE (2001) Summarizing multiple aspects of model performance in a single diagram. J Geophys Res Atmospheres 106(D7):7183-7192

van Griensven A, Meixner T, Grunwald S, Bishop T, Diluzio A, Srinivasan R (2006) A global sensitivity analysis tool for the parameters of multi-variable catchment models. J Hydrol 324(1-4):10-23. doi:10.1016/j.jhydrol.2005.09.008

Wang X, Melesse AM (2005) Evaluation of the swat model's snowmelt hydrology in a northwestern Minnesota watershed. Trans Asae 48(4):1359-1376

Zhang XS, Srinivasan R, Debele B, Hao FH (2008) Runoff simulation of the headwaters of the Yellow River using the SWAT model with three snowmelt algorithms. J Am Water Resour Assoc 44(1):48-61. doi:10.1111/j.1752-1688.2007.00137.x 